\title{
Commentary: Nuisance or nemesis? Postoperative atrial fibrillation increases long-term mortality regardless of sex
}

\author{
Malak Elbatarny, MD, ${ }^{\mathrm{a}}$ Derrick Y. Tam, MD, ${ }^{\mathrm{b}}$ and Stephen E. Fremes, MD, MSc, FRCSC
}

From the a Division of Cardiac Surgery, Department of Surgery, University of Toronto, Toronto, Ontario, Canada; and ${ }^{\mathrm{b}}$ Division of Cardiac Surgery, Department of Surgery, Schulich Heart Centre, Sunnybrook Health Sciences Centre, University of Toronto, Toronto, Ontario, Canada.

Dr Tam is supported by a CIHR Fellowship (Canada). Dr Fremes is supported by the Bernard S. Goldman Chair in Cardiovascular Surgery (Toronto, Ontario, Canada).

Disclosures: Authors have nothing to disclose with regard to commercial support.

Received for publication May 21, 2019; accepted for publication May 23, 2019; available ahead of print June 28, 2019.

Address for reprints: Stephen E. Fremes, MD, MSc, FRCSC, Sunnybrook Health Sciences Centre, 2075 Bayview Ave, Room H4 05, Toronto, Ontario M4N 3M5, Canada (E-mail: stephen.fremes@ sunnybrook.ca).

J Thorac Cardiovasc Surg 2020;159:1426-7

0022-5223/\$36.00

Copyright $($ C 2019 by The American Association for Thoracic Surgery

https://doi.org/10.1016/j.jtcvs.2019.05.058

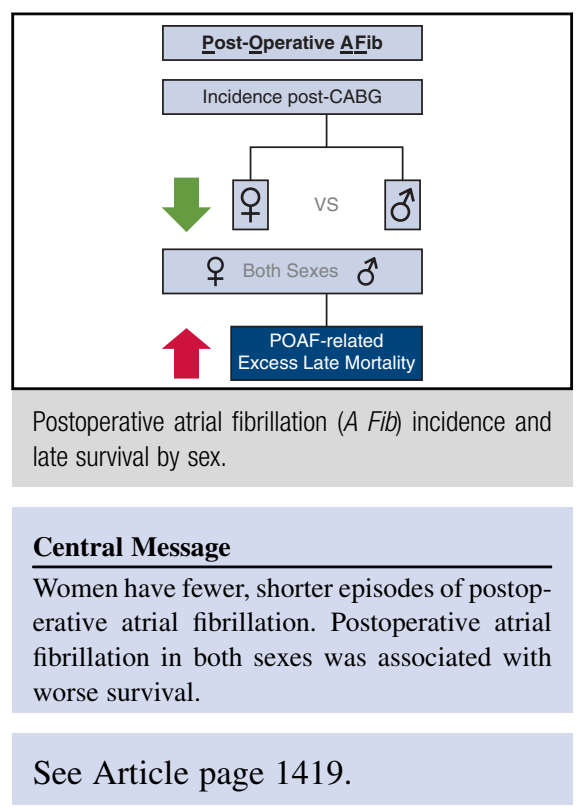

Postoperative atrial fibrillation (POAF) complicates approximately $30 \%$ of coronary artery bypass grafting (CABG) procedures. ${ }^{1}$ POAF has been associated with perioperative adverse outcomes including stroke, reoperation for bleeding, myocardial infarction, and pacemaker use. ${ }^{1,2}$ Patients with POAF are known to have a significantly increased risk of mortality in short-term, midterm, and long-term follow-up. POAF also lengthens hospital stay by 3 to 5 days and increases hospitalization cost from $\$ 10,000$ to $\$ 20,000$ per patient. ${ }^{3}$ Although female sex has been found to be protective against new-onset atrial fibrillation, ${ }^{4}$ in general, studies continue to demonstrate poorer outcomes of women after cardiac surgery. ${ }^{5-8}$ The effect of sex on POAF represents an interesting area of study.

We congratulate Filardo and colleagues ${ }^{9}$ on their study in this issue of the Journal addressing this topic. Filardo and colleagues ${ }^{9}$ report a multicenter propensity score-adjusted study comparing the incidence of POAF, perioperative outcomes, and 9-year survival of men and women undergoing CABG. The study investigated 9203 patients from 4 US centers. POAF, defined as any episode detected by electrocardiogram or telemetry during the index hospitalization, regardless of intervention, occurred in $32 \%$ of the study population, which is consistent with literature-reported values. POAF risk in women was $5 \%$ less than that in men (33\% in men vs $27 \%$ in women; $P=.04)$ in adjusted analyses. Although in-hospital mortalities was equivalent in men and women without POAF $(<1 \%)$, there was a trend towards higher risk of in-hospital death among women with POAF than among men with POAF (odds ratio, 2.49; $95 \%$ confidence interval, $0.94-6.56 ; P=.06$ ). The proportion of patients discharged home in atrial fibrillation was $2.6 \%$. POAF was associated with increased mortality at 9 years (hazard ratio, 1.56; 95\% confidence interval, 1.45-1.67). This was equivalently high among men (hazard

ratio, $1.57 ; 95 \%$ confidence interval, 1.49-1.65) and women (hazard ratio, 1.54; 95\% confidence interval 1.14-2.07).

This study must be interpreted in the context of a few limitations. First, the study period (2002-2010) may not reflect contemporary CABG practice and POAF management, particularly with the advent of direct oral anticoagulants. Importantly, studying only predischarge POAF may underestimate incidence. Remote telemetry monitoring after cardiac surgery is currently being investigated in a randomized, controlled trial (NCT02793895); however there is already evidence that atrial fibrillation is underdetected in patients with a recent cryptogenic ischemic stroke or transient ischemic attack. A randomized clinical trial comparing 30-day loop recorder monitoring versus $24 \mathrm{Hol}-$ ter monitoring showed that an absolute difference of $13 \%$ in the detection of atrial fibrillation with 30-day monitoring. ${ }^{10}$ Filardo and colleagues ${ }^{9}$ performed propensity score adjustment on the basis of relevant risk factors; however, this did not include duration of cardiopulmonary bypass, number of grafts, or completeness of revascularization. These factors both potentially affect the development of atrial fibrillation and may differ by sex. Indeed, studies have shown that female patients receive fewer arterial and total grafts. ${ }^{6,8} \mathrm{We}$ applaud Filardo and colleagues ${ }^{9}$ for diligently performing linkage to a death registry to ascertain survival. Late events such as thromboembolism, bleeding, and stroke, which 
were not studied, may be key to explaining the observed excess mortality associated with POAF. Finally, there is a lack of information regarding atrial fibrillation management in this study. Regarding pharmacologic management, a randomized clinical trial comparing rhythm with rate control in 523 patients with POAF showed no difference in freedom from atrial fibrillation at 60 days between the 2 groups, suggesting that either treatment may be effective in managing POAF. ${ }^{11}$ Despite treatment effectively restoring sinus rhythm in more than $94 \%$ and more than $84 \%$ at 30 and 60 days, ${ }^{11}$ respectively, we still find POAF to be associated with excess late mortality, and the long-term effect of potential differential treatment by sex remains unknown.

An interesting paradox was found by Filardo and colleagues. ${ }^{9}$ Although Filardo and colleagues ${ }^{9}$ show that POAF is associated with poorer late survival in women and men, and of similar magnitude, they also showed that the early burden of POAF was less in women than menwomen had fewer episodes and shorter duration of atrial fibrillation episodes. These findings appear discrepant. There is evidence that women with atrial fibrillation are less likely to undergo cardioversion than men, ${ }^{12}$ which reiterates the potential undertreatment of women with advanced cardiac disease that has been pervasively demonstrated in the literature. Although Filardo and colleagues ${ }^{9}$ do not report treatment outcomes, differential treatment could be a missing link between lower burden of POAF and equally poor survival compared with men. ${ }^{13}$

In summary, this is the first propensity-adjusted study to compare post-CABG atrial fibrillation incidence by sex and examine survival as late as 9 years. This important study affirms that POAF is more nemesis than nuisance; its strong adverse effect on long-term survival regardless of sex, despite its lower incidence in women, should prompt further investigation into pathophysiologic mechanisms and optimal management.

\section{References}

1. Shen J, Lall S, Zheng V, Buckley P, Damiano RJ Jr, Schuessler RB. The persistent problem of new-onset postoperative atrial fibrillation: a single-institution experience over two decades. J Thorac Cardiovasc Surg. 2011;141:559-70.

2. Hashemzadeh K, Dehdilani M, Dehdilani M. Postoperative atrial fibrillation following open cardiac surgery: predisposing factors and complications. J Cardiovasc Thorac Res. 2013;5:101-7.

3. Greenberg JW, Lancaster TS, Schuessler RB, Melby SJ. Postoperative atrial fibrillation following cardiac surgery: a persistent complication. Eur J Cardiothorac Surg. 2017;52:665-72.

4. Pothineni NV, Vallurupalli S. Gender and atrial fibrillation: differences and disparities. US Cardiol Rev. 2018;12:1

5. Chung J, Stevens LM, Ouzounian M, El-Hamamsy I, Bouhout I, Dagenais F, et al. Sex-related differences in patients undergoing thoracic aortic surgery. Circulation. 2019;139:1177-84.

6. Nicolini F, Vezzani A, Fortuna D, Contini GA, Pacini D, Gabbieri D, et al. Gender differences in outcomes following isolated coronary artery bypass grafting: long-term results. J Cardiothorac Surg. 2016;11:10-4.

7. Saxena A, Dinh D, Smith JA, Shardey G, Reid CM, Newcomb AE. Sex differences in outcomes following isolated coronary artery bypass graft surgery in Australian patients: analysis of the Australasian Society of Cardiac and Thoracic Surgeons cardiac surgery database. Eur J Cardiothorac Surg. 2012;41:755-62.

8. Arif R, Farag M, Gertner V, Szabó G, Weymann A, Veres G, et al. Female gender and differences in outcome after isolated coronary artery bypass graft surgery: does age play a role? PLoS One. 2016;11:e0145371.

9. Filardo G, Ailawadi G, Pollock BD, da Graca B, Phan TK, Thourani V, et al. Postoperative atrial fibrillation: sex-specific characteristics and effect on survival. $J$ Thorac Cardiovasc Surg. 2020;159:1419-25.e1.

10. Gladstone DJ, Spring M, Dorian P, Panzov V, Thorpe KE, Hall J, et al. Atrial fibrillation in patients with cryptogenic stroke. N Engl J Med. 2014;370:2467-77.

11. Gillinov AM, Bagiella E, Moskowitz AJ, Raiten JM, Groh MA, Bowdish ME, et al; CTSN. Rate control versus rhythm control for atrial fibrillation after cardiac surgery. N Engl J Med. 2016;374:1911-21.

12. Schnabel RB, Pecen L, Ojeda FM, Lucerna M, Rzayeva N, Blankenberg S, et al Gender differences in clinical presentation and 1-year outcomes in atrial fibrillation. Heart. 2017;103:1024-30.

13. Hessian R, Jabagi H, Ngu JM, Rubens FD. Coronary surgery in women and the challenges we face. Can J Cardiol. 2018;34:413-21. 